\title{
Cesarean Scar Ectopic Pregnancy: Case Report and Review of the Literature
}

\author{
${ }^{1}$ Shashidhar Boraiah, ${ }^{2}$ Thankam Varma, ${ }^{3}$ Kundavi Shankar
}

\begin{abstract}
Cesarean scar ectopic pregnancy is becoming increasingly common in tertiary care hospitals. Cesarean scar pregnancy is a rare type of ectopic pregnancy associated with complications, such as uterine rupture, uncontrollable bleeding which may lead to hysterectomy and increased maternal morbidity and mortality and subsequent infertility. Options available for treatment, such as dilatation and curettage, excision of trophoblastic tissues using laparotomy or laparoscopy, systemically administered methotrexate, and more recently uterine artery embolization. We report two such cases between 2012 and 2013 managed conservatively.
\end{abstract}

Keywords: Ectopic pregnancy, Methotrexate.

How to cite this article: Boraiah S, Varma T, ShankarK. Cesarean Scar Ectopic Pregnancy: Case Report and Review of the Literature. J South Asian Feder Obst Gynae 2016;8(1):66-68.

Source of support: Nil

Conflict of interest: None

Date of received: 20 December 2015

Date of acceptance: 13 February 2016

Date of publication: March 2016

\section{INTRODUCTION}

Uterine scar pregnancy is a gestation separated from the endometrial cavity and completely surrounded by the myometrium and the fibrous tissue of the scar. The most probable mechanism through which this can occur is invasion of the myometrium through a microscopic tract. The tract is believed to develop from trauma from previous uterine surgeries like dilatation and curettage, myomectomy, metroplasty and cesarean section. ${ }^{1}$

Although implantation of a pregnancy within the scar of a previous cesarean section is the rarest form of ectopic

${ }^{1}$ Associate Consultant, ${ }^{2} \mathrm{Head},{ }^{3}$ Senior Consultant

${ }^{1}$ Department of Obstetrics and Gynecology, Institute of Reproductive Medicine, Madras Medical Mission, Chennai Tamil Nadu, India

${ }^{2,3}$ Department of Reproductive Medicine, Institute of Reproductive Medicine, Madras Medical Mission, Chennai, Tamil Nadu India

Corresponding Author: Shashidhar Boraiah, Associate Consultant, Department of Obstetrics and Gynecology, Institute of Reproductive Medicine, Madras Medical Mission, Chennai Tamil Nadu, India, Phone: 9790978841, e-mail: shashi180808@ gmail.com pregnancy, ${ }^{2}$ it is important to consider this possibility in patients with the above-mentioned risk factors. This is because early diagnosis with an ultrasound scan can offer treatment options capable of avoiding uterine rupture and hemorrhage and, hence, preserve the uterus.

\section{CASE REPORTS}

\section{Case 1}

Mrs X aged 40-year-old G2P1L1 with previous lower segment cesarean section with secondary subfertility conceived with infertility treatment (frozen embryo replacement). Transvaginal ultrasound at 8 weeks suggested gestational sac measuring $25 \times 15 \mathrm{~mm}$ with surrounding chorionic tissue, extending into the cervico isthmic junction at the scar area anteriorly. Color Doppler showed mild vascularity in chorionic tissue with absent cardiac activity suggestive of miscarriage as seen in Figure 1. The diagnosis was revised to that of a cesarean scar ectopic pregnancy. The patient was counseled about the diagnosis. A decision was made for conservative management with methotrexate. Her blood tests including complete blood count, renal function test, and liver function tests were found to be normal. Her beta human chorionic gonadotropin (hCG) at admission was 90,926 IU/1. She was treated with 2 doses of intramuscular methotrexate injection. She was followed up with serial beta hCG and transvaginal scan. Her beta hCG dropped to $24,963 \mathrm{IU} / 1$ 1057.1 IU/1 and $7.74 \mathrm{IU} / 1$ on 8 th, 18th and 42nd post-treatment days. Transvaginal scan on 26th post-treatment day showed hemorrhagic collection in the lower part of cervical canal. She is well on follow-up and her follow-up hysteroscopy showed normal cavity.

\section{Case 2}

Mrs Y aged 31-year-old G5P1LIE1 with spontaneous conception, with diabetes mellitus on insulin was seen at 6 weeks of gestation. Her scan revealed gestational sac of $5 \times 3 \mathrm{~mm}$ with yolk sac at the lower end of endometrial cavity. Her review scan a week later suggested $6 \times 5 \mathrm{~mm}$ gestational sac with yolk sac with absent fetal pole. Sac is located $4 \mathrm{~mm}$ from the anterior uterine serosa suggestive of scar implantation as seen in Figures 2 and 3. She was counseled for conservative management after explaining the risks. Her initial beta hCG was 10,340 IU/1 and baseline blood tests were within normal limits. She 


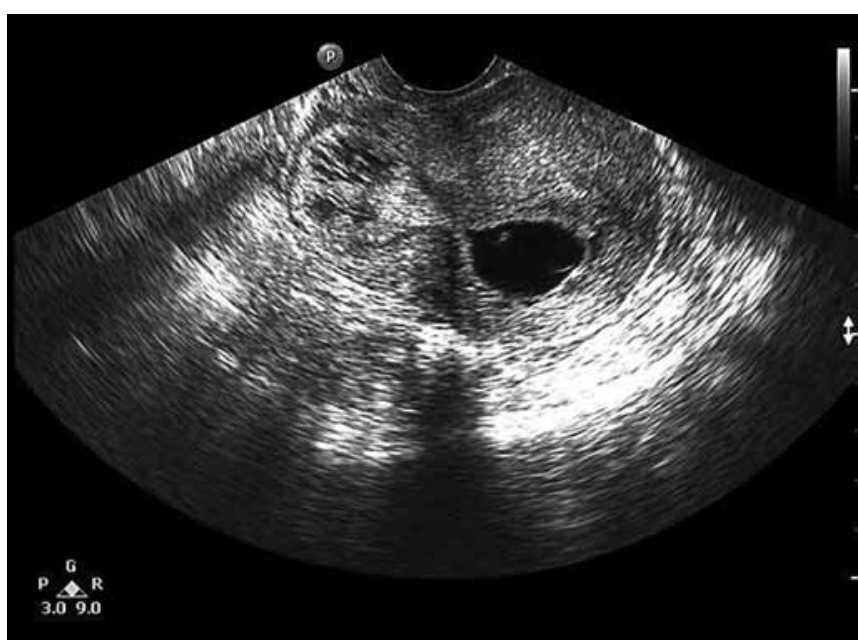

Fig. 1: Mrs X' TVS shows intrauterine gestational sac and part of chorionic tissue is imaged in the previous LSCS scar region slightly invaginating into the anterior wall

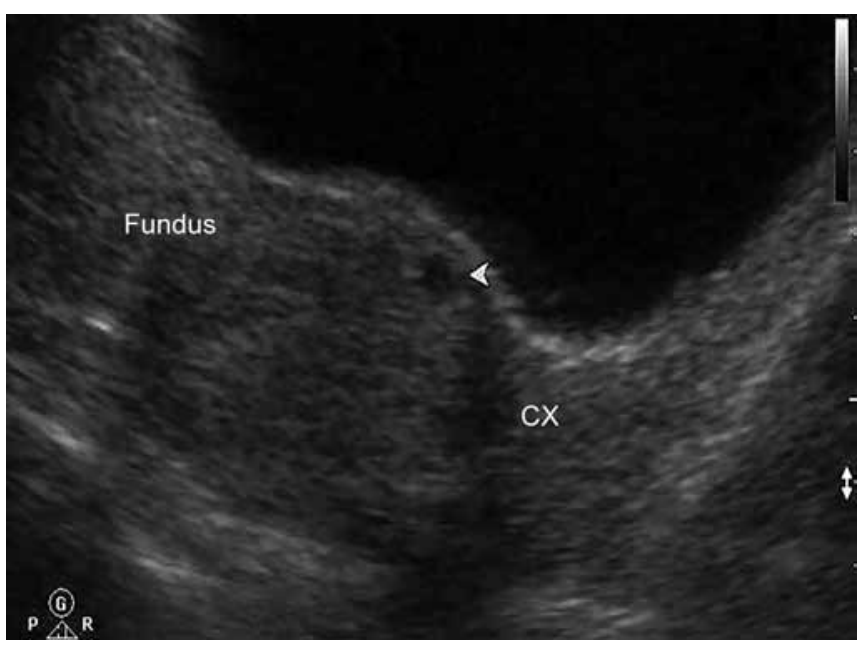

Fig. 3: Mrs Y' TAS sac is located anteriorly and $4 \mathrm{~mm}$ from uterine serosa adjacent to bladder anteriorly. No intrauterine pregnancy was identified

received two doses on intramuscular methotrexate. She expelled some products which was consistent with products of conception on histopathology (Fig. 4). Her follow-up beta hCG showed decreasing trend and 4,742.1 IU/1 and $632 \mathrm{IU} / 1$ on 14th and 30th post-treatment days. Her follow-up scans showed hCG showing decreasing trend and decreasing size of gestational sac. She is well on follow-up.

\section{DISCUSSION}

Cesarean scar pregnancies represent less than $1 \%$ of all pregnancies; however, the rate is definitely increasing due to the increasing cesarean section rates. If left untreated, the condition is frequently complicated by first-trimester uterine rupture, profuse hemorrhage, and possible emergency hysterectomy. A cesarean scar pregnancy is a gestation completely surrounded by myometrium and the fibrous tissue of the cesarean section scar is separated from the endometrial cavity and

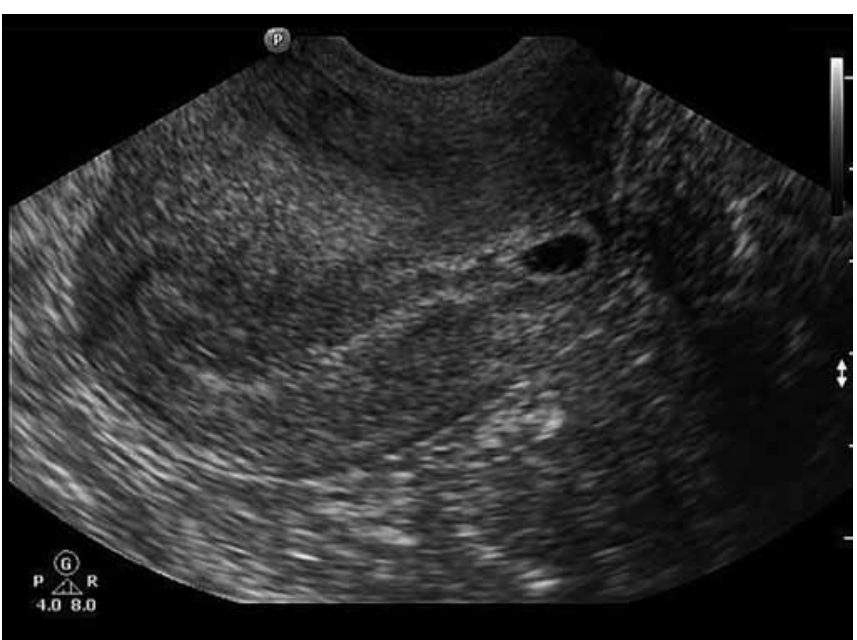

Fig. 2: Mrs Y'TVS shows gestational sac of $5 \times 3 \mathrm{~mm}$ with yolk sac at the lower end of endometrial cavity

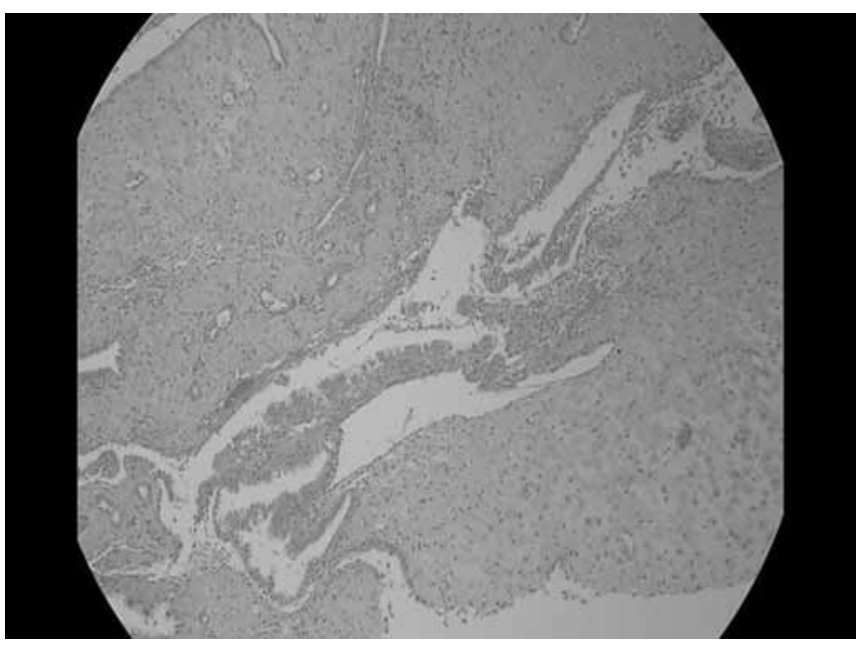

Fig. 4: Mrs Y' chorionic villus lined by double layer of trophoblasts, many syncytial trophoblasts are also visualized

endocervical canal. Expectant management of a viable scar pregnancy puts the mother at significant risk of an emergency hysterectomy if the pregnancy progresses beyond the first trimester. ${ }^{3}$ The pathophysiology of cesarean scar pregnancy remains to be established, but it is possible that the conceptus penetrates the myometrium through a microscopic dehiscent tract of the cesarean scar $^{4}$ or the gestational sac implantation occurs in a poor healed cesarean section scar. It may also result from a defect in the endometrium caused by trauma created by procedures in assisted reproduction techniques. ${ }^{5}$

The natural history of this condition remains unclear, it may result in a pregnancy that looses its vascular connections while growing, thus, causing a spontaneous abortion, or it may continue to grow gaining new stronger vascular connections ending into a low-lying adherent placenta with or without invasion of surrounding organs. Most common symptom is painless vaginal bleeding that may be profuse sometimes. It has, therefore, been inferred 
by some that all scar pregnancies should be terminated once the diagnosis has been made. Endovaginal ultrasonography and color flow Doppler are essential for diagnosis. The sonographic criteria for diagnosis ${ }^{3,6}$ are: (i) empty uterus and empty cervical canal, (ii) development of the sac in the anterior wall of the isthmic portion, (iii) a discontinuity on the anterior wall of the uterus demonstrated on a sagittal plane of the uterus running through the amniotic sac, (iv) absent or diminished healthy myometrium between the bladder and the sac (v) high velocity with low impedance peritrophoblastic vascular flow clearly surrounding the sac is proposed in Doppler examination. The main management options are still surgical and nonsurgical treatments.

Seow et al in his retrospective study concluded that ultrasound-guided methotrexate injection is the treatment of choice to terminate cesarean scar pregnancy. ${ }^{7}$ The medical treatment requires a prolonged follow-up (the hCG level takes up to 4 months to return to normal) ${ }^{8}$ and implies a high cost. Bleeding may occur following the MTX injection as in the reported case, which may require surgical intervention. Failure of pregnancy resorption and persistance of a relatively large gestational sac may imply a dilatation and curettage or a laparoscopic intervention. The surgical approach includes radical and conservative procedures. The radical procedure consists in hysterectomy when the uterus is ruptured or if bleeding is uncontrollable. The conservative procedure includes (i) evacuation of the pregnancy and repair of the uterine defect by laparotomy or laparoscopy, ${ }^{9,10}$ (ii) dilatation and curettage and excision of trophoblastic tissues using laparotomy or laparoscopy. Another treatment possibility is the uterine artery embolization (UAE) which is widely accepted as a conservative treatment in postpartum hemorrhage, in uterine fibroid. Although UAE seems to be promising in treating stable cases, it is not recommended as a primary line therapy.

\section{CONCLUSION}

The diagnosis of CSP can be challenging, and awareness of this condition is needed, particularly as the incidence is increasing. There does not appear to be a clear association between number of prior cesarean deliveries and scar pregnancies. Post-treatment surveillance should include serial clinical examinations, serum $\beta$-hCG measurements repeat ultrasound examinations as indicated.

\section{REFERENCES}

1. Fait G, Goyert G, Sundareson A, Pickens A Jr. Intramural pregnancy with foetal survival: case history and discussion of etiologic factors. Obstet Gynecol 1987 Sept;70(3 Pt 2):472-474.

2. Fylstra DL. Ectopic pregnancy within a caesarean scar: a review. Obstet Gynecol Surv 2002;57:537-543.

3. Jurkovic D, Hillaby K, Woelfer B, Lawrence A, Salim R, Elson CJ. First-trimester diagnosis and management of pregnancies implanted into the lower uterine segment caesarean section scar. Ultrasound Obstet Gynecol 2003;21:220-227.

4. Godin PA, Bassil S, Donnez J. An ectopic pregnancy developing in a previous caesarian section scar.' Fertility and Sterility 1997;67(2):398-400.

5. Hamilton CJCM, Legarth J, Jaroudi KA. Intramural pregnancy after in vitro fertilization and embryo transfer.' Fertility and Sterility 1992;57(1):215-217.

6. Fylstra DL, Pound-Chang T, Miller MG, Cooper A, Miller KM. Ectopic pregnancy within a cesarean delivery scar: a case report. Am J Obstet Gynecol 2002;187(2):302-304.

7. Seow KM, Huang LW, Lin YH, Lin MY, Tsai YL, Hwang JL. Cesarean scar pregnancy: issues in management. Ultrasound Obstet Gynecol 2004 Mar;23(3):247-253.

8. Doubilet M, Benson CB, Frates MC, Ginsburg E. Sonographically guided minimally invasive treatment of unusual ectopic pregnancies. J Ultrasound Med 2004;23(3):359-370.

9. Fylstra DL, Pound-Chang T, Miller MG, Cooper A, Miller KM. Ectopic pregnancy within a cesarean delivery scar: a case report. Am J Obstet Gynecol 2002;187(2):302-304.

10. Tulpin L, Morel O, Malartic C, Barranger E. Conservative management of a cesarean scar ectopic pregnancy: a case report. Cases J 2009;2(8):Article 7794. 